Subconsciousness 



\section{Yves Agid}

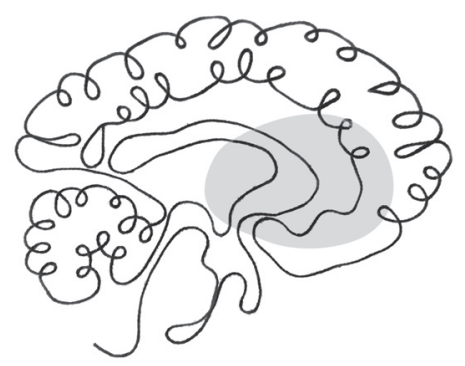

Subconsciousness

0

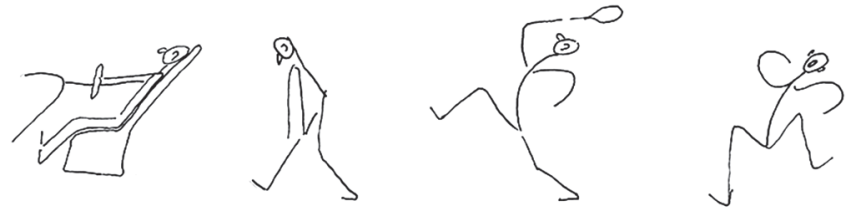

Automatic Behavior and the Brain

Columbia University Press

New York 


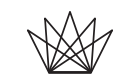

Columbia University Press

Publishers Since 1893

New York Chichester, West Sussex

cup.columbia.edu

\section{Copyright () 202I Columbia University Press}

All rights reserved

Library of Congress Cataloging-in-Publication Data Names: Agid, Yves, author.

Title: Subconsciousness : automatic behavior and the brain / Yves Agid.

Description: New York : Columbia University Press, [202I]

| Includes bibliographical references and index.

Identifiers: LCCN 2020050185 (print) | LCCN 2020050186 (ebook)

| ISBN 978023I20I26I (hardback) | ISBN 978023I20I278 (trade

paperback) | ISBN 9780231554015 (ebook)

Subjects: LCSH: Subconsciousness. | Consciousness.

| Human behavior-Psychological aspects. | Brain.

Classification: $\mathrm{LCC} \mathrm{BF}_{3} \mathrm{I}_{5}$. $\mathrm{A}_{3} 6$ 202I (print) | LCC BF315 (ebook)

| DDC I54.2-dc23

LC record available at https://lccn.loc.gov/2020050I85

LC ebook record available at https://lccn.loc.gov/2020050I86

Columbia University Press books are printed on permanent and durable acid-free paper.

Printed in the United States of America

Cover design: Lisa Hamm

Cover image: Digital composite: (top) Science Photo Library /

Alamy Stock Photo; (bottom) @ Yves Agid 
A Thomasine Kushner, ma très chère amie et ma voix 

"And what is the use of a book," thought Alice, "without pictures or conversation?"

- LEWIS CARRoll, ALICE'S ADVENTURES IN WONDERLAND 
